\title{
CANCER
}

\section{Identification of somatostatin receptor subtypes 1, 2A, 3, and 5 in neuroendocrine tumours with subtype specific antibodies}

\author{
H Kulaksiz, R Eissele, D Rössler, S Schulz, V Höllt, Y Cetin, R Arnold
}

See end of article for authors' affiliations

Correspondence to: Dr H Kulaksiz, Department of Internal Medicine, Division of Gastroenterology, Ruprecht-Karls-University, Bergheimer Str 58 D-69115 Heidelberg, Germany;

Hasan_Kulaksiz@ med.uni-heidelberg.de

Accepted for publication 12 April 2001

\begin{abstract}
Background and aims: Recently, novel somatostatin receptor (sstr) subtype specific ligand analogues have been developed for medical treatment of neuroendocrine tumours expressing different sstrs (sstr 1-5). At present, individual expression patterns of sstr subtypes are based on methods such as in situ hybridisation and polymerase chain reaction at the transcriptional level. Therefore, we generated subtype specific antibodies against sstr 1, 2A, 3, and 5 and analysed their presence, cellular localisation, distribution, and expression pattern in 33 gastrinomas, 36 insulinomas, and 35 tumours associated with a carcinoid syndrome by immunohistochemistry at the translational level.

Methods: Western blotting experiments were performed in the normal human pancreas used as a reference organ and in tumour tissues; at the cellular level, sstrs were localised by immunohistochemistry in tissue paraffin sections.

Results: In western blot analyses, the antibodies identified the respective receptors in their correct molecular range in extracts of the pancreas and neuroendocrine tumours. Using immunohistochemistry and immunofluorescence, the antibodies specifically detected the receptors in islet cells of the normal pancreas. Immunohistochemistry in the tumours revealed that all investigated sstr subtypes were highly expressed in the different tumour types. The frequency and expression pattern of the individual sstr subtypes varied considerably not only between the different tumour types but also in each patient.

Conclusions: We conclude that immunohistochemistry with subtype specific antibodies can be used in clinical routine work to analyse sstr expression patterns for each patient before treatment and to facilitate well directed individual medical therapy by administering subtype specific somatostatin analogues.
\end{abstract}

$\mathrm{N}$ euroendocrine gastroentero-pancreatic neoplasms are either characterised by production and secretion of biologically active peptides and amines which can cause distinct clinical syndromes, including peptic ulceration (gastrinoma), life threatening attacks of hypoglycaemia (insulinoma), or severe diarrhoea and flushing (tumours responsible for the carcinoid syndrome), or they are functionally inactive. ${ }^{12}$ As many patients present with metastatic disease at the time of diagnosis, they receive medical treatment for symptom control and inhibition of tumour growth. In this respect, somatostatin (SS) analogues, such as octreotide, the first analogue available for clinical use, have achieved a particular importance in the diagnosis and clinical management of these patients. ${ }^{2-4}$ The molecular rationale for the administration of octreotide and other analogues is based on the SS receptors (sstr) which have been detected in neuroendocrine tumours by autoradiography and octreotide scintigraphy. ${ }^{5}$ In fact, at least five different human sstr subclasses - that is, sstrl to 5-have been cloned and characterised. ${ }^{7-10}$ These receptors reveal distinct differences in their molecular structure, tissue distribution, intracellular signalling, and pharmacological characteristics for different SS analogues. ${ }^{11}$ All receptor subtypes bind somatostatin-14 (SS-14) with high affinity while their affinity for the SS analogues differs considerably. The agents octreotide, lanreotide, and RC-160 have comparable binding profiles and exhibit a high affinity for sstr2 and sstr 5 but show low affinity for sstr3 and no affinity for sstrl and sstr4, respectively..$^{10}$ As the absence of sstr2 in tumours is accompanied by lack of tumour response for octreotide, ${ }^{12}{ }^{13}$ it has been concluded that octreotide mediates its effects predominantly through sstr2. ${ }^{10}{ }^{14}$ Binding of sstrs by SS analogues results in inhibition of hormone hypersecretion from these tumours and of cell proliferation. ${ }^{310} 15$
Although there is a positive correlation between sstr expression in neuroendocrine tumours and the inhibitory effects of octreotide on hormone release and tumour growth during therapy, ${ }^{16}$ only some patients respond to treatment with long acting SS analogues. In this respect, development and application of novel sstr subtype specific analogues with high affinity for their receptor subtypes could be important for the treatment of sstr positive tumours in the future. ${ }^{13}$ However, this option requires identification of sstr status in each patient before treatment. At present, receptor status and individual expression patterns of sstr subtypes are detected by in situ hybridisation or polymerase chain reaction at the transcriptional level. Although sstrl and sstr2 have been detected in single tumours by immunohistology, ${ }^{17-19}$ there are no systematic data on receptor status and expression patterns of individual sstrs in neuroendocrine tumours. In particular, there are no data on sstr3 although recent studies have proposed that high dose SS analogues may induce apoptosis by binding to sstr $3 .^{2021}$

We have developed a panel of sstr subtype specific antibodies to identify the presence, cellular localisation, distribution, and tumour specific expression pattern of individual sstr proteins in a panel of neuroendocrine tumours by immunohistochemistry. Such immunohistochemical analyses of sstrs in clinical routine work may be the basis for individual diagnostic and therapeutic options for patients suffering from these tumours.

Abbreviations: SS, somatostatin; sstr, somatostatin receptor; PBS, phosphate buffered saline. 
Table 1 Receptor status of patients with gastrinomas, insulinomas, or tumours associated with a carcinoid syndrome

\begin{tabular}{|c|c|c|c|c|c|c|c|}
\hline Case No & Tumour type & $\begin{array}{l}\text { Location of investigated } \\
\text { tumour }\end{array}$ & sstr 1 & sstr2A & sstr3 & sstr5 & Octreoscan \\
\hline $1 \mathrm{KH}$ & Gastrinoma & Pancreas & + & + & + & + & ND \\
\hline $2 \mathrm{PK}$ & Gastrinoma & Pancreas & - & + & + & + & ND \\
\hline $3 \mathrm{BC}$ & Gastrinoma & Pancreas & + & + & + & + & ND \\
\hline $4 \mathrm{KS}$ & Gastrinoma & Pancreas & - & + & + & - & ND \\
\hline $5 \mathrm{HK}$ & Gastrinoma & Pancreas & - & + & - & + & ND \\
\hline $6 \mathrm{MA}$ & Gastrinoma & Pancreas & - & + & + & + & Pos \\
\hline $7 \mathrm{KH}$ & Gastrinoma & Liver (metast.) & - & + & - & + & ND \\
\hline $8 \mathrm{OE}$ & Gastrinoma & Pancreas & - & + & - & + & ND \\
\hline 9 SK & Gastrinoma & Pancreas & - & + & + & + & ND \\
\hline $10 \mathrm{HG}$ & Gastrinoma & Pancreas & - & + & - & - & ND \\
\hline $11 \mathrm{TF}$ & Gastrinoma & Pancreas & - & + & + & + & ND \\
\hline $12 \mathrm{TF}$ & Gastrinoma & Liver (metast.) & + & + & + & + & ND \\
\hline $13 S R$ & Gastrinoma & Duodenum & - & + & + & + & ND \\
\hline $14 \mathrm{TL}$ & Gastrinoma & Duodenum & + & + & + & + & ND \\
\hline $15 \mathrm{PK}$ & Gastrinoma & Duodenum & - & + & - & - & ND \\
\hline $16 \mathrm{FE}$ & Gastrinoma & Duodenum & - & + & + & + & Pos \\
\hline $17 \mathrm{MF}$ & Gastrinoma & Pancreas & - & + & + & - & Neg \\
\hline $18 \mathrm{OM}$ & Gastrinoma & Pancreas & - & + & + & + & Pos \\
\hline 19 WG & Gastrinoma & Pancreas & - & + & - & + & ND \\
\hline $20 \mathrm{LU}$ & Gastrinoma & Pancreas & - & + & + & - & ND \\
\hline $21 \mathrm{BO}$ & Gastrinoma & Pancreas & - & + & + & + & Pos \\
\hline $22 \mathrm{SH}$ & Gastrinoma & Duodenum & + & + & + & + & ND \\
\hline $23 \mathrm{MH}$ & Gastrinoma & Pancreas & + & + & + & + & ND \\
\hline $24 \mathrm{PA}$ & Gastrinoma & Pancreas & - & + & + & - & ND \\
\hline $25 \mathrm{HM}$ & Gastrinoma & Liver (metast.) & + & + & + & + & Pos \\
\hline $26 \mathrm{MA}$ & Gastrinoma & Liver (metast.) & + & + & + & + & Pos \\
\hline $27 \mathrm{OM}$ & Gastrinoma & Pancreas & - & + & + & + & ND \\
\hline 28 SK & Gastrinoma & Pancreas & - & + & + & + & ND \\
\hline 29 GS & Gastrinoma & Pancreas & + & + & + & - & ND \\
\hline 30 PK & Gastrinoma & Pancreas & - & + & + & + & Pos \\
\hline $31 \mathrm{LH}$ & Gastrinoma & Pancreas & - & + & + & + & ND \\
\hline 32 SR & Gastrinoma & Pancreas & - & + & + & + & ND \\
\hline $33 \mathrm{HK}$ & Gastrinoma & Pancreas & + & + & - & - & ND \\
\hline $34 \mathrm{OL}$ & Insulinoma & Pancreas & - & + & + & + & ND \\
\hline $35 \mathrm{AK}$ & Insulinoma & Pancreas & - & + & + & + & ND \\
\hline $36 \mathrm{MB}$ & Insulinoma & Pancreas & + & + & + & + & ND \\
\hline $37 \mathrm{RH}$ & Insulinoma & Pancreas & - & + & - & + & ND \\
\hline $38 \mathrm{MH}$ & Insulinoma & Pancreas & - & - & + & + & ND \\
\hline $39 \mathrm{ME}$ & Insulinoma & Pancreas & + & + & + & + & ND \\
\hline $40 \mathrm{BE}$ & Insulinoma & Pancreas & + & + & + & + & ND \\
\hline $41 \mathrm{KW}$ & Insulinoma & Pancreas & - & - & + & + & ND \\
\hline $42 \mathrm{WH}$ & Insulinoma & Pancreas & - & + & - & + & Pos \\
\hline $43 \mathrm{VB}$ & Insulinoma & Pancreas & - & + & + & + & ND \\
\hline $44 \mathrm{MM}$ & Insulinoma & Pancreas & - & - & + & + & $\mathrm{Neg}$ \\
\hline $45 \mathrm{SW}$ & Insulinoma & Liver (metast.) & + & + & + & + & Pos \\
\hline $46 \mathrm{DM}$ & Insulinoma & Pancreas & + & + & + & + & ND \\
\hline $47 \mathrm{SH}$ & Insulinoma & Pancreas & - & + & + & - & ND \\
\hline $48 \mathrm{KK}$ & Insulinoma & Pancreas & + & - & + & + & ND \\
\hline $49 \mathrm{HM}$ & Insulinoma & Pancreas & - & + & + & + & ND \\
\hline $50 \mathrm{WH}$ & Insulinoma & Pancreas & + & - & + & + & $\mathrm{Neg}$ \\
\hline $51 \mathrm{PL}$ & Insulinoma & Pancreas & - & + & - & - & ND \\
\hline $52 \mathrm{MH}$ & Insulinoma & Pancreas & - & + & + & - & ND \\
\hline $53 \mathrm{~GB}$ & Insulinoma & Pancreas & + & - & + & + & ND \\
\hline $54 \mathrm{RA}$ & Insulinoma & Pancreas & - & - & - & - & ND \\
\hline $55 \mathrm{ZE}$ & Insulinoma & Pancreas & - & - & + & + & ND \\
\hline $56 \mathrm{KG}$ & Insulinoma & Pancreas & - & + & - & + & Pos \\
\hline 57 RD & Insulinoma & Pancreas & - & + & + & + & ND \\
\hline $58 \mathrm{WU}$ & Insulinoma & Pancreas & - & - & + & - & ND \\
\hline $59 \mathrm{KL}$ & Insulinoma & Pancreas & - & - & - & - & ND \\
\hline 60 GK & Insulinoma & Pancreas & - & + & + & + & ND \\
\hline $61 \mathrm{SW}$ & Insulinoma & Liver (metast.) & + & + & + & + & ND \\
\hline $62 \mathrm{SW}$ & Insulinoma & Pancreas & + & - & + & + & ND \\
\hline $63 \mathrm{BC}$ & Insulinoma & Pancreas & - & - & + & + & ND \\
\hline $64 \mathrm{RE}$ & Insulinoma & Pancreas & - & - & - & - & ND \\
\hline $65 \mathrm{FJ}$ & Insulinoma & Pancreas & - & + & + & + & ND \\
\hline $66 \mathrm{OD}$ & Insulinoma & Pancreas & - & - & + & + & Neg \\
\hline $67 \mathrm{TN}$ & Insulinoma & Pancreas & + & + & - & + & ND \\
\hline 68 LG & Insulinoma & Pancreas & - & + & + & - & ND \\
\hline $69 \mathrm{AM}$ & Insulinoma & Pancreas & - & - & + & + & ND \\
\hline $70 \mathrm{KA}$ & Carcinoid & Liver (metast.) & - & + & - & + & ND \\
\hline $71 \mathrm{~L}$ & Carcinoid & Intestine & - & + & + & + & ND \\
\hline $72 \mathrm{HH}$ & Carcinoid & Intestine & + & + & + & + & Pos \\
\hline $73 \mathrm{MB}$ & Carcinoid & Duodenum & - & + & - & - & ND \\
\hline $74 \mathrm{HM}$ & Carcinoid & Liver (metast.) & - & - & + & + & ND \\
\hline $75 \mathrm{MH}$ & Carcinoid & Intestine & + & + & + & + & ND \\
\hline $76 \mathrm{GW}$ & Carcinoid & Intestine & + & + & + & + & ND \\
\hline $77 \mathrm{KK}$ & Carcinoid & Intestine & - & - & + & + & ND \\
\hline
\end{tabular}




\begin{tabular}{|c|c|c|c|c|c|c|c|}
\hline Case No & Tumour type & $\begin{array}{l}\text { Location of investigated } \\
\text { tumour }\end{array}$ & sstr 1 & sstr2A & sstr3 & sstr5 & Octreoscan \\
\hline $78 \mathrm{WH}$ & Carcinoid & Duodenum & - & + & + & + & ND \\
\hline $79 \mathrm{AL}$ & Carcinoid & Liver (metast.) & - & + & - & + & ND \\
\hline $80 \mathrm{HG}$ & Carcinoid & Intestine & + & + & + & + & Pos \\
\hline $81 \mathrm{SG}$ & Carcinoid & Intestine & + & + & - & + & ND \\
\hline 82 SG & Carcinoid & Liver (metast.) & + & + & + & + & ND \\
\hline $83 \mathrm{HM}$ & Carcinoid & Liver (metast.) & + & + & + & - & ND \\
\hline $84 \mathrm{KL}$ & Carcinoid & Duodenum & - & - & + & + & ND \\
\hline $85 \mathrm{SA}$ & Carcinoid & Intestine & - & + & + & + & ND \\
\hline $86 \mathrm{SJ}$ & Carcinoid & Intestine & - & + & + & + & Pos \\
\hline 87 LB & Carcinoid & Intestine & - & + & - & + & ND \\
\hline $88 \mathrm{ME}$ & Carcinoid & Duodenum & - & + & + & + & ND \\
\hline $89 \mathrm{MH}$ & Carcinoid & Liver (metast.) & - & + & - & + & ND \\
\hline $90 \mathrm{KU}$ & Carcinoid & Intestine & + & + & + & + & ND \\
\hline $91 \mathrm{LF}$ & Carcinoid & Intestine & - & - & - & + & Pos \\
\hline $92 \mathrm{DA}$ & Carcinoid & Intestine & + & + & + & + & Pos \\
\hline $93 \mathrm{HM}$ & Carcinoid & Intestine & + & + & + & + & ND \\
\hline 94 GK & Carcinoid & Liver (metast.) & - & + & + & + & ND \\
\hline $95 \mathrm{BE}$ & Carcinoid & Intestine & - & + & + & + & Pos \\
\hline $96 \mathrm{AU}$ & Carcinoid & Duodenum & - & + & + & + & ND \\
\hline $97 \mathrm{HU}$ & Carcinoid & Intestine & - & + & - & - & ND \\
\hline $98 \mathrm{HK}$ & Carcinoid & Liver (metast.) & + & + & + & - & ND \\
\hline $99 \mathrm{DA}$ & Carcinoid & Duodenum & + & + & - & - & ND \\
\hline $100 \mathrm{IH}$ & Carcinoid & Intestine & - & + & - & + & ND \\
\hline $101 \mathrm{DM}$ & Carcinoid & Intestine & + & + & + & - & Pos \\
\hline $102 \mathrm{DE}$ & Carcinoid & Intestine & - & + & + & + & ND \\
\hline $103 \mathrm{HS}$ & Carcinoid & Intestine & - & + & + & + & ND \\
\hline $104 \mathrm{HM}$ & Carcinoid & Intestine & - & - & + & + & ND \\
\hline
\end{tabular}

ND, not done; Pos, positive; Neg, negative; sstr, somatostatin receptor

The term carcinoid, as used here, refers to tumors that secrete serotonin and are associated with the carcinoid syndrome.

\section{METHODS}

\section{Patients, tumours, and tissue preparation}

Neuroendocrine tumours from 33 patients with gastrinoma, 36 patients with insulinoma, and 35 patients with carcinoid syndrome (for details see table 1) were studied. The respective diagnoses were made on the presence of classical clinical symptoms (gastrinoma: peptic ulceration; insulinoma: hypoglycaemia; carcinoid tumour: severe diarrhoea and/or flush), laboratory findings, and immunohistopathological investigations (Grimelius staining, immunohistochemistry for chromogranin A, neurone specific enolase, synaptophysin, serotonin, gastrin, SS, vasoactive intestinal peptide, glucagon, insulin, and pancreatic polypeptide). In addition, some patients were subjected to SS receptor scintigraphy with $\left[{ }^{111}\right.$ In-DTPA-D-Phe $\left.{ }^{1}\right]$ octreotide.

Tumour samples were obtained by surgical tumour resection performed between 1983 and 1998 at the Department of General Surgery, Philipps University, Marburg, Germany. Neoplastic tissues were resected from the centre of the respective tumours to exclude contamination with normal tissue. Normal tissue was separated beyond the tumour margins and confirmed to be histologically normal. After resection, tissues were fixed in Bouin's fixative for immunohistochemistry or immediately frozen in liquid nitrogen for western blot analyses. Pertinent data from patient histories (diagnosis, tumour location, octreoscan) are summarised in table 1 . In some cases, patients were treated with octreotide but the tissues investigated in the present study were all obtained before medical treatment.

\section{Peptide synthesis, immunisation procedure, and antisera generation}

The following peptides were synthesised as detailed previously ${ }^{22}$ (Gramsch Laboratories, Schwabhausen, Germany) with reference to the published human SS sequences ${ }^{7-9}$ : sstrl (377-391), sstr2A (355-369), sstr3 (381-395), and sstr5 (350-364). After purification by high performance liquid chromatography, the peptides were coupled to keyhole limpet haemocyanin (Sigma Chemical Co, St Louis, Missouri, USA) via an amino terminally added cysteine and a succinimidyl 4-[N-maleimidomethyl]cyclohexane-1-carboxylate linker. Rabbits (Zikahybrid) were immunised subcutaneously with the respective peptide conjugates emulsified in complete Freund's adjuvant at $1: 1$ ( $\mathrm{vol} / \mathrm{vol})$. They were given booster injections every four weeks and bled 14 days after each booster injection. The titre of the generated antibodies was checked by enzyme linked immunosorbent assay. Of the antibodies raised, antibodies 4819 recognising sstrl (377-391), 6291 raised against sstr2A (355-369), 4823 against sstr3 (381-395), and 6006 against sstr5 (350-364) exhibited the highest titres. These antibodies have been used and characterised in detail on sstr transfected HEK-293 cells, in immunoblot analyses, and in immunohistochemistry. ${ }^{22-24}$

\section{Protein preparation from tissues and western blot procedure}

Proteins from pancreas and tumour tissues were extracted using a Tris $\mathrm{HCl}$ buffer containing $10 \mathrm{mM}$ Tris $\mathrm{HCl}, \mathrm{pH} 7.4,250$ mM sucrose, 1 mM EDTA, 1\% Triton X-100, $2 \mu \mathrm{g} / \mathrm{ml}$ leupeptin, 2 $\mu \mathrm{g} / \mathrm{ml}$ pepstatin, and $1 \mathrm{mM}$ phenylmethylsulphonylfluoride. For western blot analysis, $25 \mu \mathrm{g}$ of total protein (measured by the Lowry method) were separated on $8 \%$ sodium dodecyl sulphate-polyacrylamide gels. Separated proteins were transferred onto hydrophobic polyvinylidene fluoride based membranes and incubated with the various antisera at dilutions also used for immunohistochemistry (see below). The respective immunoreactive proteins were visualised after incubation with alkaline phosphatase conjugated goat antirabbit IgG (diluted 1:30 000; Sigma) using nitroblue tetrazolium and 5-bromo-4chloro-3-indolyl phosphate as chromogens (Sigma). The immunoreaction in western blots was specifically blocked after preincubation of the antibodies with the corresponding peptide immunogens. Any cross reactions with the second goat antirabbit antibodies were excluded by appropriate controls. ${ }^{25} 26$

\section{Immunohistochemistry and immunofluorescence}

Immunohistochemistry was performed in tissue specimens from the primary tumours or from liver metastases when the 


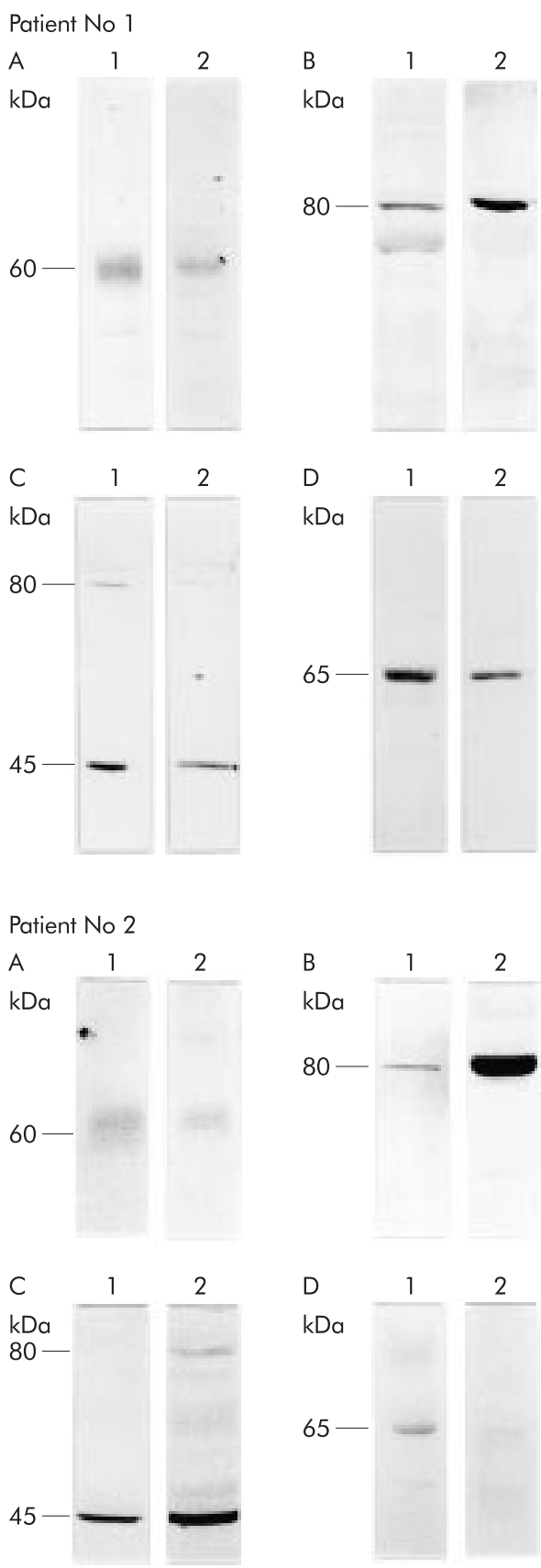

Figure 1 Western blot analyses of somatostatin receptor (sstr) subtypes sstr 1 (A), sstr2A (B), sstr3 (C), and sstr5 (D) in normal human pancreas (lanes 1) and in pancreatic insulinoma (lanes 2) of the same patient. Note that immunoreactive sstrs of the tumour tissue comigrate with the immunoreactive sstrs of the pancreas used as the reference organ.

tumours were metastasised. Tissues were fixed for 20 hours in Bouin's fixative, dehydrated, and embedded in paraffin. The sections $(5 \mu \mathrm{m})$ were immunostained using the avidin-biotinperoxidase complex $(\mathrm{ABC})$ technique, as detailed previously $^{25-27}$ : sections were dewaxed with xylene, rehydrated in a graded series of ethanol, and microwaved in $10 \mathrm{mM}$ citric acid (pH 6.0) for 20 minutes at $600 \mathrm{~W}$. After blocking of unspecific binding sites with 3\% bovine serum albumin for 30 minutes, sections were incubated with the respective antisera (sstr antibodies 4819, 6291, 4823, and 6006, each diluted 1:500; antibodies against chromogranin A, neurone specific enolase, synaptophysin, gastrin, SS, glucagon, insulin, and pancreatic polypeptide for tumour identification were purchased from
A

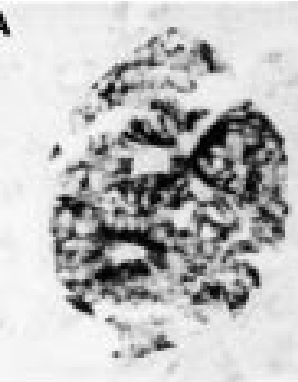

B

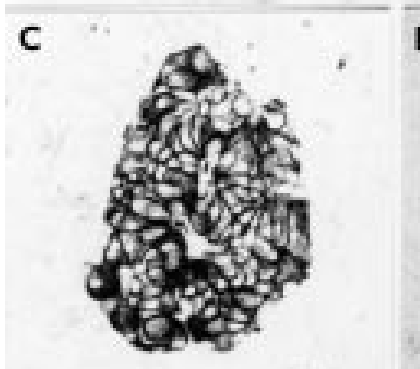

D

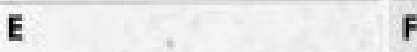

$\mathbf{F}$

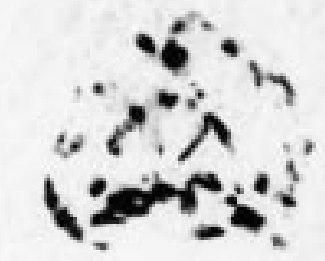

G.

H
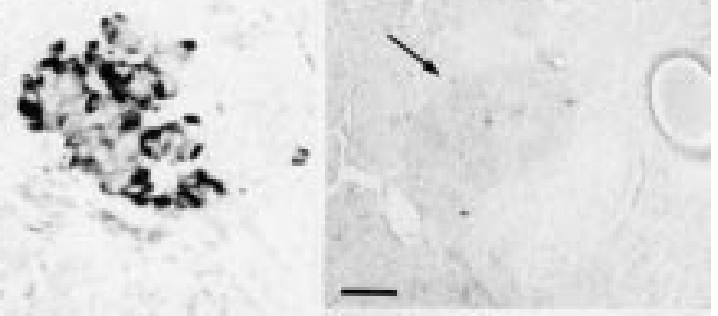

Figure 2 Localisation of the somatostatin receptor (sstr) subtypes in normal human pancreas using immunohistochemistry. All receptor subtypes ((A) sstr l; (C) sstr2A; (E) sstr3; (G) sstr5) are clearly localised in pancreatic islet cells. Note that immunostaining in the islets (arrows) is completely blocked by preabsorption of the antibodies ((B) sstr l; (D) sstr2A; (F) sstr3; (H) sstr5). (Scale bars: A, $C$, $E$, and $G=20 \mu m ; B, D, F$, and $H=30 \mu \mathrm{m}$.)

Dako (Hamburg, Germany), diluted 1:1000-1:4000; antibodies against serotonin and vasoactive intestinal peptide were purchased from Sorin (Düsseldorf, Germany), diluted 1:10001:10 000) overnight at $4^{\circ} \mathrm{C}$, followed by incubation with biotinylated antirabbit IgG (Dako) for 30 minutes in a dilution of $1: 200$. The sections were then incubated for 30 minutes with a preformed complex of biotin-peroxidase/streptavidin (Dako), diluted in phosphate buffered saline (PBS) (final concentrations: biotin-peroxidase $0.7 \mu \mathrm{g} / \mathrm{ml}$; streptavidin $5 \mu \mathrm{g} / \mathrm{ml}$ ). The antigen-antibody binding sites were visualised by incubation of the sections in $0.7 \mathrm{mM}$ diaminobenzidine hydrochloride/ $0.002 \% \mathrm{H}_{2} \mathrm{O}_{2}$ in $0.05 \mathrm{M}$ Tris $\mathrm{HCl}(\mathrm{pH}$ 7.6). PBS was used as the diluent for the antisera and as a rinsing solution. Alternatively, the receptors were detected by immunofluorescence microscopy by incubation of the sections with the same sstr antibodies overnight at $4^{\circ} \mathrm{C}$, followed by incubation with $\mathrm{Cy} 3$ labelled 

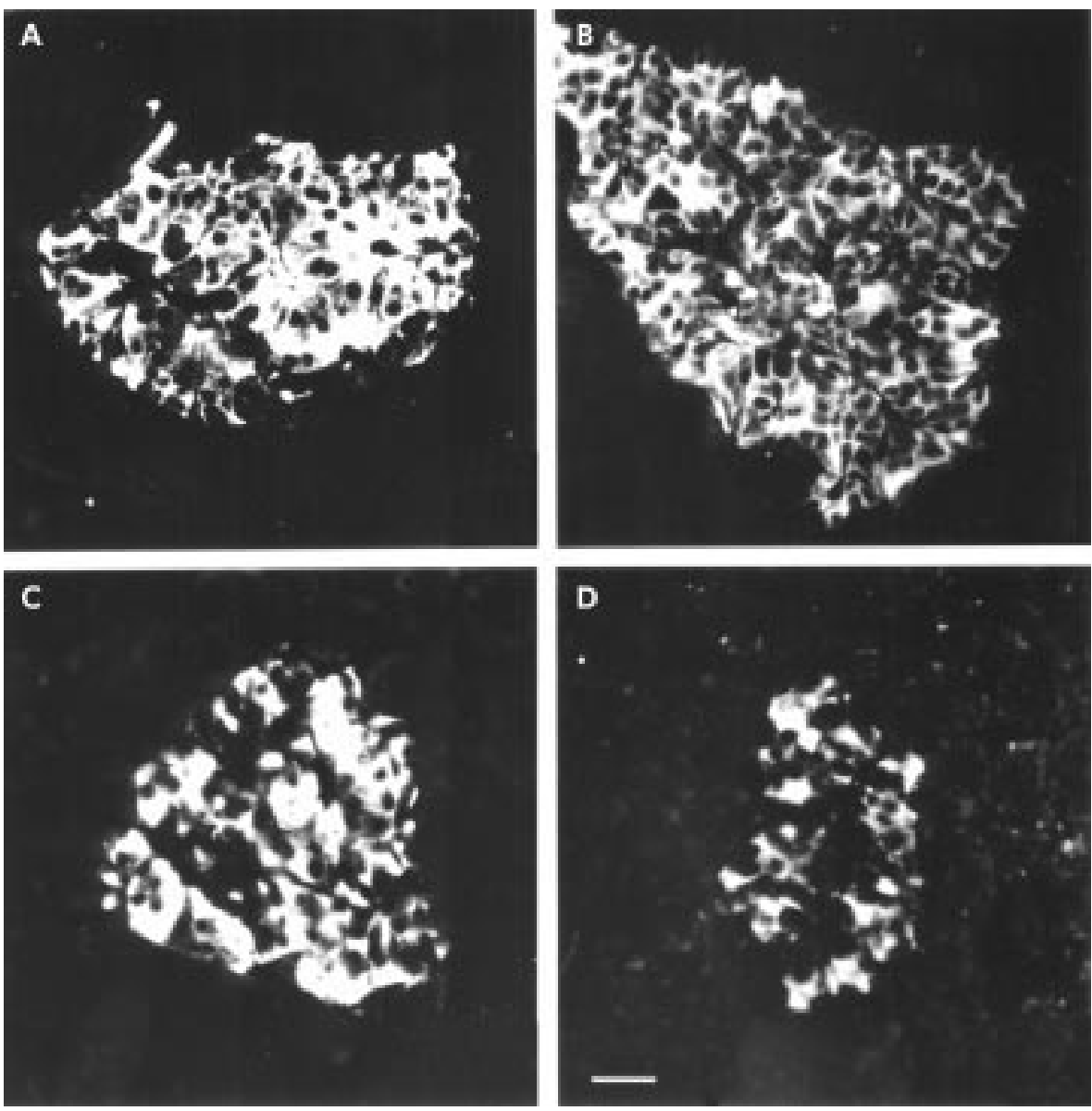

Figure 3 Localisation of the somatostatin receptor (sstr) subtypes in normal pancreas using immunofluorescence. Note that all sstr subtypes ((A) sstr 1 ; (B) sstr2A; (C) sstr3; (D) sstr4) are clearly localised in pancreatic islet cells. (Scale bar A-D=20 $\mu \mathrm{m}$.)

antirabbit IgG (Dianova, Hamburg, Germany) diluted 1:200. The immunostainings were investigated in a Zeiss Axioplan microscope equipped with appropriate filters.

Although all tissue sections were treated equally (same duration of fixation, immunohistochemical protocol, and antibody dilution), significant differences were obtained in sstr expression. Tumours were categorised as negative for sstr immunoreactivity when no immunostaining was observed, even with a high power objective, despite unequivocal immunostaining for the neuroendocrine tumour markers (see above).

\section{Specificity controls}

With respect to the immunoreactivities obtained, nonspecificities in the immunohistochemical protocol were excluded by running the following controls ${ }^{25}{ }^{26}$ : (i) omission of single steps in the immunohistochemical protocol, (ii) addition of polylysine $\left(M_{r} 15000 ; 2 \mathrm{mg} / \mathrm{ml}\right.$; Sigma $)$ to the first antibody, and (iii) use of high molar (0.5 M) PBS as a rinsing solution between the various steps of the immunohistochemical protocol. Specificities of the antibodies were tested by preadsorption of all antisera with homologous and heterologous antigenic peptides $(6.25-100 \mu \mathrm{g} / \mathrm{ml}$ of the antiserum). ${ }^{25}{ }^{26}$ Preabsorption of the antisera with homologous antigens at concentrations as low as $6.25 \mu \mathrm{g} / \mathrm{ml}$ completely blocked immunostaining in the pancreatic tissues and tumours, while preadsorption of the antisera with heterologous antigens at concentrations of up to $100 \mu \mathrm{g} / \mathrm{ml}$ had no effect on immunostaining.

\section{Statistical evaluation}

Data were analysed by $\chi^{2}$ test for independence. Differences were considered significant at $\mathrm{p}<0.01$.

\section{RESULTS}

Human neuroendocrine tumours were identified as gastrinoma, insulinoma, and carcinoid tumours by histopathological investigations. Although some of these tumours were not of a single cell type, the respective diagnoses were made according to classical clinical symptoms of the tumours and laboratory findings.

To analyse the presence, cellular localisation, and tumour specific expression patterns of the sstr subtypes in these tumours, we raised a panel of subtype specific antisera against sstrl, 2A, 3, and 5 and used them in western blotting analyses and immunohistochemistry. In western blot analyses of normal pancreatic tissues, the antibody 4819 raised against sstrl and antibody 6006 raised against sstr5 identified the immunoreactive proteins of $\sim 60$ and $\sim 65 \mathrm{kDa}$, respectively (fig 1). The antibody 6291 raised against sstr2A detected the respective immunoreactive protein in the range of $\sim 80 \mathrm{kDa}$ molecular mass. Similarly, the antibody 4823 identified sstr3 at $\sim 80$ and $\sim 45 \mathrm{kDa}$ molecular mass. In addition, all sstr antibodies recognised immunoreactive proteins with identical molecular sizes in gastrinomas, insulinomas, and carcinoid tumours (fig l).

In normal pancreatic tissues, used as positive controls, immunohistochemical and immunofluorescence investigations with the subtype selective sstr antibodies revealed strong immunoreactivity in the islet cells with a unique pattern of cellular distribution for each sstr subtype. While immunoreactivity for sstrl, 3, and 5 was detected in the cytoplasm and partly on the membrane of islet cells, clear sstr2A immunostaining was predominantly localised on the plasma membrane of the cells (figs 2,3). Preabsorption of the antibodies 


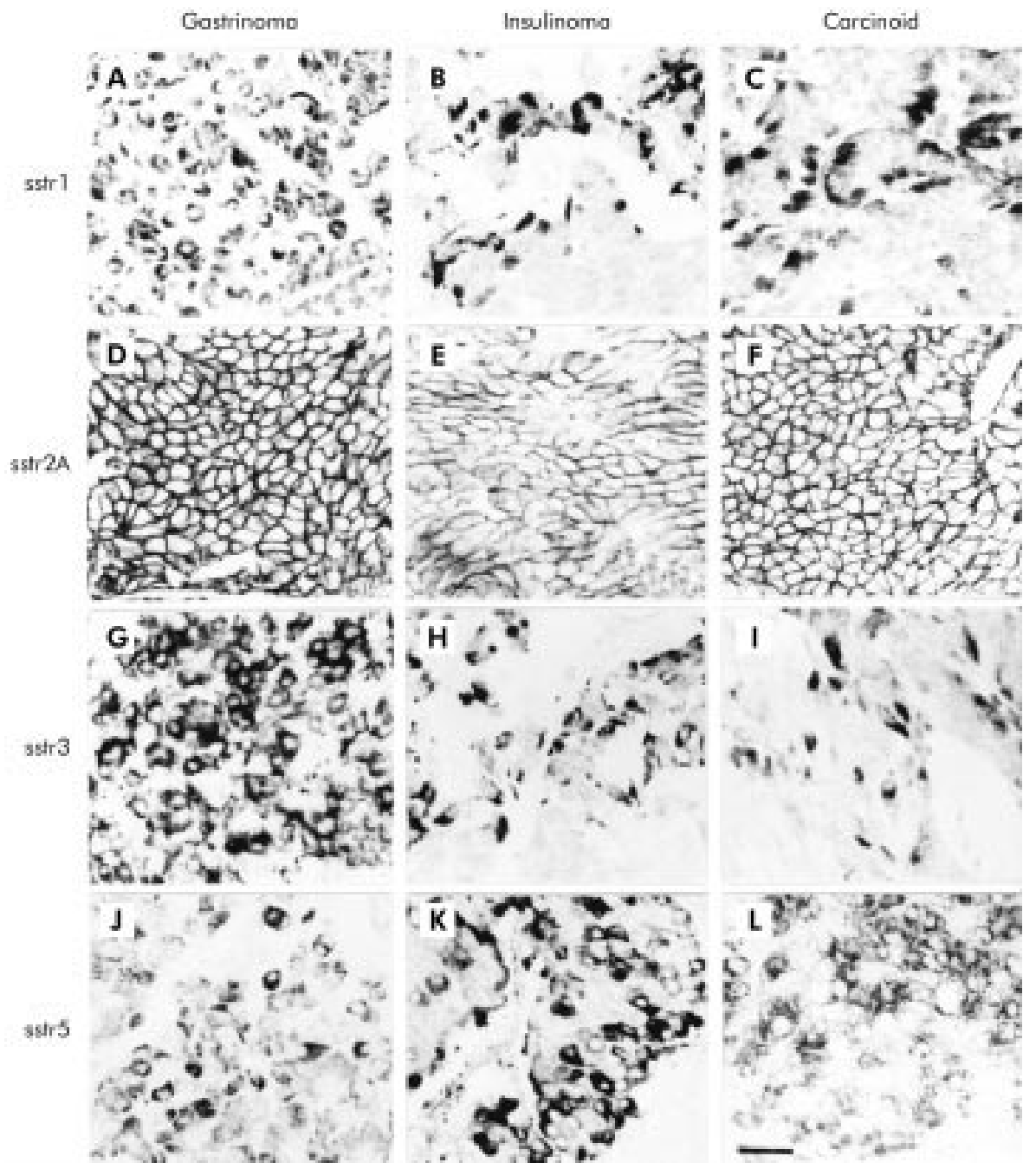

Figure 4 Immunohistochemical localisation of the somatostatin receptor (sstr) subtypes in gastrinoma, insulinoma, and carcinoid tumour. Although all sstr subtypes are expressed in the respective neuroendocrine tumours, individual expression patterns of the subtypes vary greatly between the tumour types. (Scale bar $A-L=30 \mu \mathrm{m}$.)

with the corresponding antigens completely blocked immunostaining in the pancreatic tissues (fig 2).

Immunohistochemistry in the neuroendocrine tumours revealed that sstrl, 2A, 3, and 5 were all highly expressed in gastrinomas, insulinomas, carcinoid tumours, and their respective liver metastases (fig 4). Although in the majority of positively stained tumours sstr immunoreactivity for the various subtypes was obtained in most tumour cells, a considerable part of the tumours showed no homogenous staining; immunoreactivity for sstrs was concentrated on groups of cell clusters in these tumours. At the cellular level, sstr2A was localised exclusively on the plasma membrane of neoplastic cells; in no case was sstr2A found in the cytoplasm (figs 4-6). In contrast, sstrl, 3, and 5 showed immunostaining mainly in the cytoplasm (figs 4-6).

Interestingly, in the different tumours, the expression pattern at the cellular level and also the frequency of receptor expression between the sstr subtypes varied greatly (table 1). While sstrl immunoreactivity was present in $10(30 \%)$ gastrinomas, $11(31 \%)$ insulinomas, and $13(37 \%)$ carcinoid tumours, sstr2A was expressed in all (100\%) gastrinomas, 21 (58\%) insulinomas, and 30 (86\%) carcinoid tumours. Staining for sstr3 was observed in $26(79 \%)$ gastrinomas, $28(78 \%)$ insulinomas, and $25(71 \%)$ carcinoid tumours; and sstr5 immunoreactivity was detected in 25 (76\%) gastrinomas, 28 $(78 \%)$ insulinomas, and $29(83 \%)$ carcinoid tumours. However, with the exception of sstr2A, no significant differences were seen for the frequency of receptor expression regarding tumour type or tumour location. The sstr subtypes were present constantly in all tumour types originating from the pancreas or intestine. Regarding sstr2A, expression was by far less frequent in insulinomas than in gastrinomas or carcinoid tumours.

Of 104 patients included in this study, 22 were subjected to sstr octreotide scintigraphy. Comparative analyses revealed a high correlation between scintigraphy and sstr2A immunohistochemistry; in only two cases was the outcome of sstr scintigraphy not consistent with the results of immunohistochemistry.

\section{DISCUSSION}

Based on expression of SS receptors sstr2 and 5, long acting SS analogues such as octreotide, lanreotide, and RC-160, which bind to sstr2 and sstr5, have become increasingly important in the symptomatic management of patients with neuroendocrine tumours. ${ }^{310}$ However, a considerable part of such tumours do not respond to the current therapy. ${ }^{13}$ In this respect, the potential value of subtype specific SS analogues is under intensive discussion, ${ }^{14}$ especially as the various sstr subtypes seem to be involved in different pathways for inhibition of hormone secretion or of cell proliferation and apoptosis. ${ }^{1020}{ }^{21}$ Although the presence of sstr mRNAs has been examined in various tumours ${ }^{10}$ using costly methods such as 


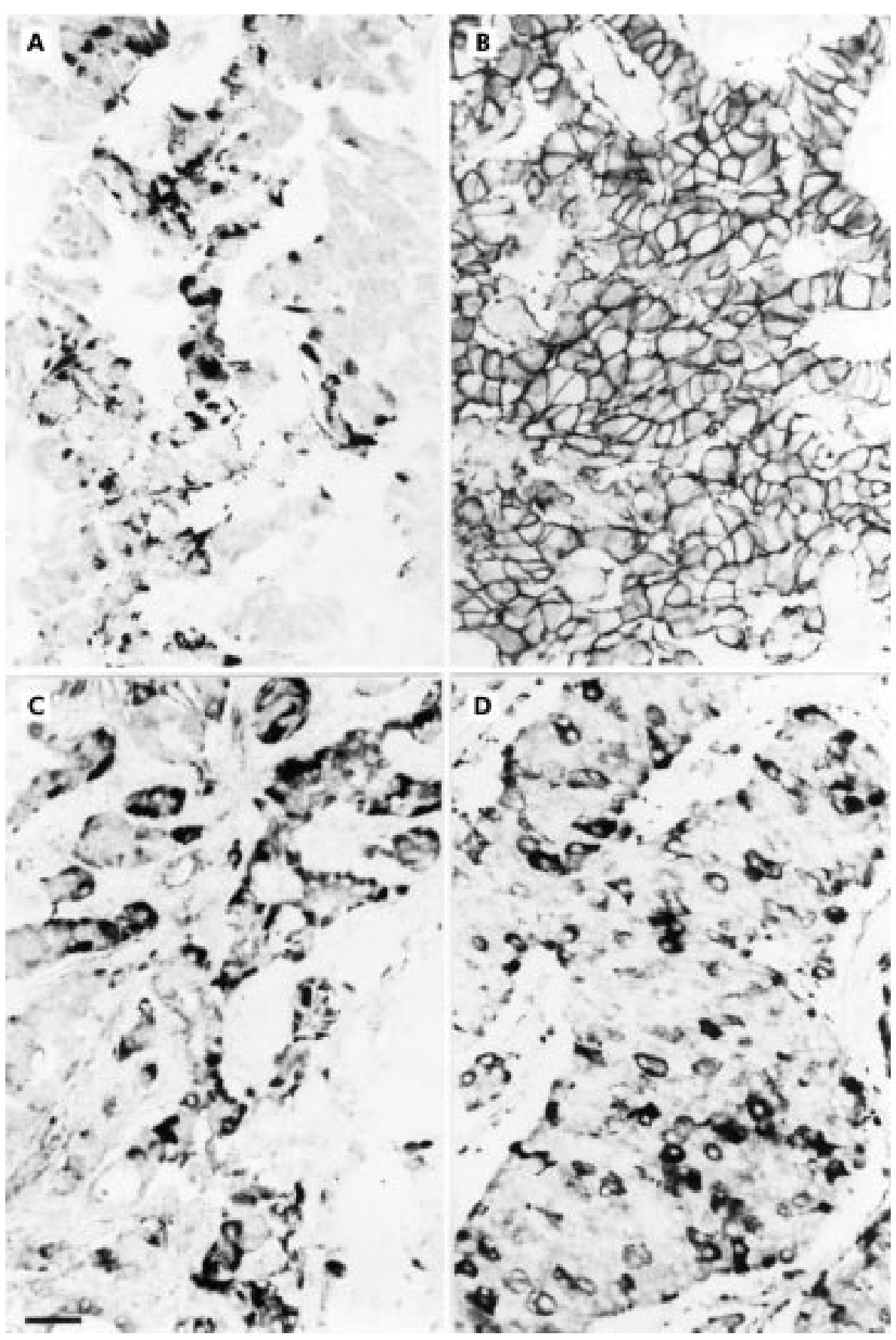

Figure 5 Immunohistochemical localisation of the somatostatin receptor (sstr) subtypes in an insulinoma showing that sstr 1 (A), sstr3 (C), and sstr5 (D) are detected in single cells which are surrounded by non-immunostained tumour cells. In contrast, sstr2A (B) is present in nearly all tumour cells. (Scale bar A-D=30 pm.)

in situ hybridisation, there are no data on the receptor status characterising the expression pattern of individual sstr subtypes in neuroendocrine tumours at the translational level. In the present study, we raised subtype specific antibodies against sstrl, 2A, 3, and 5 and analysed systematically their presence, cellular localisation, distribution, and individual expression pattern in gastrinomas, insulinomas, and carcinoid tumours by immunohistochemistry.

These antibodies are specific for the respective sstr subtypes without any cross reactions. In western blot analyses of normal human pancreas known to express the various sstr subtypes, ${ }^{28}$ the sstrl antibody 4819 and sstr5 antibody 6006 clearly identified the immunoreactive proteins in the range $\sim 60$ and $\sim 65$ $\mathrm{kDa}$, respectively, which corresponds with the molecular mass of these subtypes. ${ }^{10}$ The antibody 6291 specifically identified sstr2 $\mathrm{A}$ as expected at $\sim 80 \mathrm{kDa}$. Indeed, sstr2 in the range of 80 $\mathrm{kDa}$ has been reported to occur as a glycosylated form of this protein. ${ }^{10} 29$ Similarly, the sstr3 antibody 4823 identified the immunoreactive proteins at $\sim 80 \mathrm{kDa}$ and, in addition, distinctly at $\sim 45 \mathrm{kDa}$ molecular mass, which corresponds with that of glycosylated $s$ str $3^{10}$ and with that deduced from the respective cDNA sequence, ${ }^{8}$ respectively.

Remarkably, all sstr antibodies also detected the respective proteins in tissue extracts of gastrinomas, insulinomas, and carcinoid tumours which exactly comigrated with the immunoreactive bands in the normal human pancreas. These findings indicate that the SS receptor subtypes are not only present in the pancreas, they are also highly expressed in neuroendocrine tumours. 


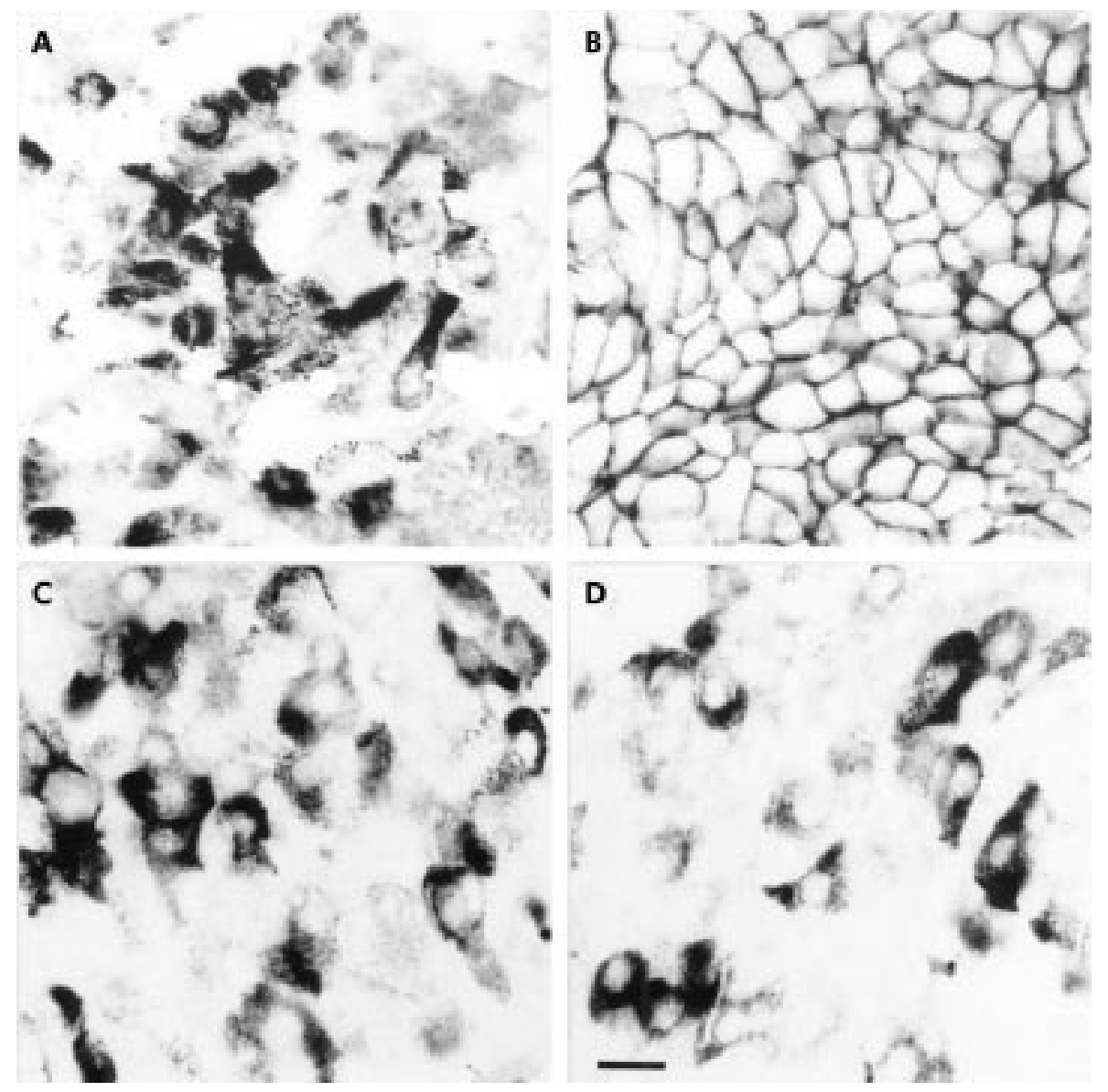

Figure 6 Subcellular localisation of the somatostatin receptor (sstr) subtypes in an insulinoma by immunohistochemistry. While sstr 1 (A), sstr3 $(C)$, and sstr5 (D) are localised mainly in the cytoplasm of neoplastic cells, sstr2A (B) immunoreactivity is exclusively detected at the plasma membrane of tumour cells in all tumour types. (Scale bar $A-D=12 \mu \mathrm{m}$.)

To test their suitability for immunohistochemistry in Bouin fixed paraffin sections, firstly, antibodies were employed in immunostainings of normal human pancreas. They revealed clear strong staining of pancreatic islet cells, as expected from previous studies. ${ }^{28}{ }^{30}$ The distribution pattern of immunopositive cells showed that A, B, and D cells were stained by the respective antisera. In immunohistochemical investigations of tumour tissues from patients with neuroendocrine tumours, the sstr antibodies yielded specific immunostainings in neoplastic cells not only in carcinoid tumours as shown for sstr $2 \mathrm{~A}^{1731}$ but also in gastrinomas, insulinomas, and their respective liver metastases. While immunoreactivity was homogenous in the majority of tumours, a considerable part of the neoplasms showed immunostaining confined to a few cell clusters of the tissues, indicating that the density of the receptors varied greatly between patients. Interestingly, immunoreactivity for the receptor subtypes 1, 3, and 5 was mainly localised in the cytoplasm; sstr2A immunoreactivity was exclusively confined to the cell membrane in all tumour types expressing this receptor. These differential locations may be due to differences in synthesis activity, intracellular targeting mechanisms, or internalisation of certain receptor subtypes. In this respect, our antibodies against sstrl, 3, and 5 may identify preferentially internalised receptors. Regarding sstr2A, localisation of this receptor only at the cell membrane may be due to our antibody detecting exclusively the integral membrane form of the receptor in the tumours or it may be because of rapid targeting and integration of this receptor subtype into the cell membrane. Thus cytoplasmic forms of the receptor would escape detection by the antibody. Indeed, the latter explanation seems to be quite plausible as previous immunohistochemical analyses of sstr2A by various researchers have shown that strong sstr immunoreactivity was mainly found at the plasma membrane of tumour cells. ${ }^{17}{ }^{31}$

Remarkably, the different SS receptor subtypes showed different expression patterns in various tumours and even within the same tumour type (see table 1). Moreover, in five patients no immunostaining was detected for sstrl, 3, or 5; these patients expressed only the receptor sstr $2 \mathrm{~A}$. In one case, sstr5 was present alone, and in a further two cases (insulinomas) none of the investigated sstr subtypes was expressed by the tumour cells. These findings reveal that the receptor status of patients differs considerably; one patient with a neuroendocrine tumour may express multiple sstr subtypes at the same time as an individual expression pattern and thus peculiar receptor status. Accordingly, determination of this expression pattern for each patient before treatment is of particular clinical importance.

Notably, the frequency of sstr expression varied significantly between the different sstr subtypes and for sstr2A also between the different tumour types. While sstr2A was present in $86 \%$ of carcinoid tumours and even in $100 \%$ of gastrinomas, it was detected in only $58 \%$ of insulinomas. As $50 \%$ of insulinomas do not respond to octreotide treatment, as shown previously, ${ }^{20} 32$ the absence of sstr2A in these patients may explain the lack of any pharmacological effect of this drug binding predominantly to the receptor subtype 2 . In contrast, more than $90 \%$ of gastrinomas responded adequately, improving clinical symptoms when treated with octreotide, ${ }^{13}$ confirming the high expression rate of sstr2A in this tumour type.

For visualisation of sstr positive tumours, SS receptor scintigraphy with [ ${ }^{111}$ In-DTPA-D-Phe ${ }^{1}$ octreotide was performed in some cases. There was a high correlation between sstr2A staining by immunohistochemistry and tracer uptake at SS receptor 
scintigraphy, as expected from previous investigations. ${ }^{17}$ However, as $\left[{ }^{111}\right.$ In-DTPA-D-Phe $\left.{ }^{1}\right]$ octreotide can bind to sstr2 and 5, and to a lesser degree to sstr $3,{ }^{46}$ this technique proved ineffective in the determination of the sstr subtypes expressed by the tumour. Therefore, immunohistochemical analysis of the sstrs is more suitable and powerful in determining the expression pattern of the receptors and can take the place of octreotide scintigraphy in this regard. In addition, immunohistochemical detection of individual sstr expression pattern may also be important for tumour biology and growth behaviour of neuroendocrine tumours as these factors seem to be dependent on the individual sstr status of the tumours. ${ }^{10}$

In conclusion, many patients suffering from neuroendocrine tumours lack any response to octreotide therapy. But in patients with negative octreotide scintigraphy, iodinated SS itself (SS-14 or SS-28) was shown to specifically bind to SS receptors. ${ }^{33}{ }^{34}$ This differential binding between octreotide and SS-14/SS-28 ligands in these patients suggests that octreotide does not bind to all sstr subtypes and that new sstr subtype selective analogues should be created for the treatment of patients with tumours expressing sstr of this particular subtype. Indeed, highly specific analogues for the respective sstr subtypes were developed very recently to achieve more effective pharmacotherapy. ${ }^{35}$ As the present study showed, sstr subtype specific antibodies may be used in clinical routine work to determine individual SS receptor status for each patient before treatment. As expression of individual sstr subtypes varies in different tumour types and even in each patient, immunohistochemical determination of these receptors is of particular clinical importance for well directed individual planning of medical treatment. Future studies should analyse the outcome of SS analogue therapy in relation to the density of respective sstrs determined by immunohistochemistry.

\section{ACKNOWLEDGMENTS}

We thank Mrs D Bonorden (Department of Gastroenterology, Philipps University, Marburg) for her expert technical assistance and Mrs I Böddeker (Institute for Medical Biometry and Epidemiology, Philipps University, Marburg) for statistical calculations. This study was supported by the Research Pool of the Philipps University Marburg, grant SCHU 924/4-1 (SS), from the Deutsche Forschungsgemeinschaft, and grant QRTL-1999-00908 (SS) from the European Commission.

\section{Authors' affiliations}

H Kulaksiz, Department of Internal Medicine, Division of Gastroenterology, Ruprecht-Karls-University, Heidelberg, Germany

R Eissele, D Rössler, R Arnold, Department of Internal Medicine,

Division of Gastroenterology and Endocrinology, Philipps University, Marburg, Germany

S Schulz, V Höllt, Department of Pharmacology and Toxicology, Otto von Guericke University, Magdeburg, Germany

Y Cetin, Department of Molecular Cell Biology, Institute of Anatomy and Cell Biology, Philipps University, Marburg, Germany

\section{REFERENCES}

1 Jensen R. Pancreatic endocrine tumors: Recent advances. Ann Oncol 1999;10:S170-6.

2 Öberg K. Neuroendocrine gastrointestinal tumors-a condensed overview of diagnosis and treatment. Ann Oncol 1999;10:S3-8.

3 Arnold R, Trautmann ME, Creutzfeldt W, et al. Somatostatin analogue octreotide and inhibition of tumour growth in metastatic endocrine gastroenteropancreatic tumours. Gut 1996;38:430-8

4 van Eijck $\mathrm{CHJ}$, de Jong M, Breeman WAP, et al. Somatostatin receptor imaging and therapy of pancreatic endocrine tumors. Ann Oncol 1999; 10:S177-81

5 Reubi JC, Kvols LK, Waser B, et al. Detection of somatostatin receptors in surgical and percutaneous needle biopsy samples of carcinoids and islet cell carcinomas. Cancer Res 1990;50:5969-77.

6 Krenning EP, Kwekkeboom DJ, Bakker WH, et al. Somatostatin receptor scintigraphy with [ ${ }^{11}$ In-DTPA-D-Phe $\left.{ }^{1}\right]$ and $\left[{ }^{123} \mathrm{Tyr}^{3}\right]$ octreotide. The Rotterdam experience with more than 1000 patients. Eur J Nucl Med 1993;20:16-731.
7 Yamada $\mathrm{Y}$, Post SR, Wang $\mathrm{K}$ et al. Cloning and functional characterization of a family of human and mouse somatostatin receptors expressed in brain, gastrointestinal tract, and kidney. Proc Natl Acad Sci USA 1992; 89:251-5

8 Yamada Y, Reisine T, Law SF, et al. Somatostatin receptors, an expanding gene family: Cloning and functional characterization of human SSTR3, a protein coupled to adenylate cyclase. Mol Endocrinol 1992;6:2136-42

9 Panetta R, Greenwood MT, Warszynska A, et al. Molecular cloning, functional characterization, and chromosomal localization of a human somatostatin receptor (somatostatin receptor type 5) with preferential affinity for somatostatin-28. Mol Pharmacol 1994;45:417-27.

10 Patel YC. Somatostatin and its receptor family. Frontiers Neuroendocrinol 1999;20:157-98.

11 Reisine T, Bell GI. Molecular biology of somatostatin receptors. Endocrine Rev 1995;16:427-42.

12 Lamberts SWJ, Krenning EP, Reubi JC. The role of somatostatin and its analogs in the diagnosis and treatment of tumors. Endocrinol Rev $1991 ; 12: 450-82$

13 Eriksson B, Öberg K. Summing up 15 years of somatostatin analog therapy in neuroendocrine tumors: Future outlook. Ann Oncol 1999; 10:S31-8.

14 Hofland LJ, Lamberts SWJ. Somatostatin analogs and receptors. Diagnostic and therapeutic applications. In: Andrew A, ed. Endocrine neoplasms. Amsterdam: Kluwer Acadamic Publishers, 1997;163-76.

15 Arnold R, Frank M. Gastrointestinal endocrine tumours: medical management. Baillieres Clin Gastroenterol 1996:10:737-59.

16 Lamberts SWJ, Hofland LJ, van Koetsveld PM, et al. Parallel in vivo and in vitro detection of functional somatostatin receptors in human endocrine pancreatic tumors: consequences with regard to diagnosis, localization, and therapy. J Clin Endocrinol Metab 1990;71:566-74.

17 Janson ET, Stridsberg M, Gobl A, et al. Determination of somatostatin receptor subtype 2 in carcinoid tumors by immunohistochemical investigation with somatostatin receptor subtype 2 antibodies. Cancer Res 1998;58:2375-78

18 Hofland LJ, Liu Q, van Koetsveld PM, et al. Immunohistochemical detection of somatostatin receptor subtypes sstl and sst2A in human somatostatin receptor positive tumors. J Clin Endocrinol Metab 1999;84:775-80.

19 Reubi JC, Kappeler A, Waser B, et al. Immunohistochemical localization of somatostatin receptors sst2A in human tumors. Am J Pathol 1998; 153:233-45

20 Imam $\mathbf{H}$, Eriksson B, Lukinius A, et al. Induction of apoptosis in neuroendocrine tumors of the digestive system during treatment with somatostatin analogs. Acta Oncol 1997;36:607-14

21 Sharma K, Patel YC, Srikant CB. Subtype-selective induction of wild-type p53 and apoptosis, but not cell cycle arrest, by human somatostatin receptor 3. Mol Endocrinol 1996;10:1688-96.

22 Schulz S, Schulz S, Schmitt J, et al. Immunocytochemical detection of somatostatin receptors sst1, sst2A, sst2B, and sst3 in paraffin-embedded breast cancer tissue using subtype-specific antibodies. Clin Cancer Res 1998:4:2047-52

23 Schulz S, Pault SU, Schulz S, et al. Immunohistochemical determination of five somatostatin receptors in meningeoma reveals frequent overexpression of somatostatin receptor subtype $2 \mathrm{~A}$. Clin Cancer Res 2000;6: 1865-74

24 Schulz S, Schreff $M$, Schmidt $H$, et al. Immunocytochemical localization of somatostatin receptor sst2A in the spinal cord and dorsal root ganglia. Eur J Neurosci 1998;10:3700-8

25 Cetin Y, Kuhn M, Kulaksiz H, et al. Enterochromaffin cells of the digestive system: Cellular source of guanylin, a guanylate cyclase-activating peptide. Proc Natl Acad Sci USA 1994:91:2935-9.

26 Cetin Y, Kulaksiz H, Redecker P, et al. Bronchiolar nonciliated secretory (Clara) cells: Source of guanylin in the mammalian lung. Proc Natl Acad Sci USA 1995;92:5925-9.

27 Kulaksiz H, Arnold R, Göke B, et al. Expression and cell-specific localization of the cholecystokinin $\mathrm{B} /$ gastrin receptor in the human stomach. Cell Tissue Res 2000;299:289-98

28 Kumar U, Sasi R, Suresh S, et al. Subtype-selective expression of the five somatostatin receptors (hSSTR 1-5) in human pancreatic islet cells. Diabetes 1999;48:77-85

29 Schonbrunn A. Somatostatin receptors present knowledge and future directions. Ann Oncol 1999;10:S17-21.

30 Koerker DJ, Ruch W, Chideckel E, et al. Somatostatin: hypothalamic inhibitor of the endocrine pancreas. Science 1974;184:482-3.

31 Kimura N, Pilichowska M, Date F, et al. Immunohistochemical expression of somatostatin type $2 \mathrm{~A}$ receptor in neuroendocrine tumors. Clin Cancer Res 1999:5:3483-7.

32 Scarpignato $\mathrm{C}$. Somatostatin analogues in the management of endocrine tumors of the pancreas. In: Mignon M, Jensen RT, eds. Endocrine fumors of the pancreas. Basel: Karger, 1995;385-414.

33 Reubi JC, Laissue J, Krenning E, et al. Somatostatin receptors in human cancer: Incidence, characteristics, functional correlates and clinical implications. J Steroid Biochem Mol Biol 1992;43:27-35

34 Reubi JC, Krenning E, Lamberts SWJ, et al. In vitro detection of somatostatin receptors in human tumors. Metabolism 1992;41:104-10.

35 Rohrer SP, Birzin ET, Mosley RT, et al. Rapid identification of subtype-selective agonists of the somatostatin receptor through combinatorial chemistry. Science 1998;282:737-40. 